\title{
Novel Compact Wide-band Substrate Integrated Waveguide Bandpass Filter using Conductor Backed Coplanar Waveguide as Feed line for W-Band Communication Applications
}

\author{
Aman Kumari \\ Department of Electronics and \\ Communication Engineering, \\ IFTM University, Moradabad, \\ U.P., India
}

\author{
Anand Pratap Singh \\ Student Member IEEE \\ Department of Electronics and \\ Communication Engineering, \\ Maharaja Surajmal Institute of \\ Technology, \\ Delhi, India \\ Dhirendra Kumar \\ Member IEEE \\ Department of Electronics and \\ Communication Engineering, \\ RKGIT, Ghaziabad, India
}

\author{
Arun Kumar \\ Department of Electronics and \\ Communication Engineering, \\ IFTM University, Moradabad, \\ U.P., India
}

\begin{abstract}
In this paper a novel compact Substrate Integrated Waveguide (SIW) filter is proposed. A wideband band pass filter for microwave and millimeter-wave systems is investigated at 80 $\mathrm{GHz}$ center frequency with $10.5 \%$ fractional bandwidth. A Conductor backed coplanar waveguide is inserted in Substrate Integrated Waveguide (SIW) structure as transition to achieve sharper skirt characteristics. Simulated results show good passband characteristics over a frequency range $75.9 \mathrm{GHz}$ to $84.3 \mathrm{GHz}$ depicting $0.1 \mathrm{~dB}$ insertion loss and minimum of 56 $\mathrm{dB}$ return loss.
\end{abstract}

\section{Keywords}

Millimeter-wave, Substrate Integrated Waveguide (SIW), Bandpass filter, Coplanar waveguide, W-Band.

\section{INTRODUCTION}

Metallic wave guide are used for transmitting electromagnetic energy. But they are bulky and expensive to manufacture. These waveguides also exhibit various losses such as copper loss, dielectric loss and radiation loss [1][2]. An alternative option to metallic waveguides is synthesized called substrate integrated waveguides (SIW). SIW is designed with linear array of metallic cylindrical holes known as posts are implanted inside the same substrate along the side walls of substrate. SIW filter shows many advantages over microstrip line filters and metallic waveguide filter such as low loss, high qualify factor, compact size, light weight and easy to integrate and fabricate with other planar and non-planar circuits. After the development of laminated waveguide various efforts have been made to the progress of SIW technology [3]. SIW technology found applications in various microwave and millimeter wave circuits components including various passive and active SIW components such as millimeter-wave resonators [4],oscillators[ 5], power dividers [6], phase shifters [7], antennas [8], circulators [9],diplexers [10] and directional couplers [11]. Filters are backbone of microwave and millimeter-wave communication systems. A lot of work has been done by many researchers in designing SIW filters.
SIW is a high pass filter as it inherits high pass characteristics of conventional waveguide and bandpass characteristics of periodic structures [12]. Various wideband bandpass filters are realized with different geometrical parameters [13]. To improve the response SIW filters with defected grounds [14], complementary split ring resonators [15] and multi-layered substrate integrated waveguide elliptic filters [16][17] have been designed. To minimize the size of filters double folded SIW resonators developed using LTCC (low temperature cofired technology) [18]. To improve quality factor half mode substrate integrated waveguide (HMSIW) is synthesized on planar substrate [19]. Planar bandpass filters using hybrid structure of SIW and coplanar waveguides are designed [20]. Filters in ultra wide band range are also designed. In this paper a compact SIW wideband bandpass filter from 75.9 $\mathrm{GHz}$ to $84.3 \mathrm{GHz}$ frequency range with fractional bandwidth of $10.5 \%$ is investigated. The filter exhibit good pass band characteristics with $0.1 \mathrm{~dB}$ insertion loss and minimum $56 \mathrm{~dB}$ return loss, which is suitable for use in various microwave and millimeter-wave circuits.

\section{DESIGN ANALYSIS}

SIW structure is a progression between microstrip and dielectric filled waveguide (DFW). SIW is a linear periodic arrangement of metallic vias or holes which are embedded along the side walls of waveguide. SIW structure supports the propagation of quasi transverse electric (TE) modes. Microstrip lines and coplanar waveguides (CPWs) are integrated to SIW as feed lines. These are transition system to connect easily with other circuits. When boundary conditions are applied to a section of SIW, a cavity resonator is obtained. The resonant frequency is given by Changjun Liu [21]:

$$
f_{\text {mon }}=\frac{c}{2 \sqrt{E_{\text {eff }}}} \sqrt{\left(\frac{m}{a}\right)^{2}+\left(\frac{n}{b}\right)^{2}}
$$

Where $\mathrm{m}, \mathrm{n}$ represents the mode number, $E_{\text {eff }}$ is the effective permittivity, $\mathrm{a}$ and $\mathrm{b}$ are longer and wider dimensions, $\mathrm{c}$ is the speed of light in free space respectively. 
Various electromagnetic field distributions along with their modes determine the resonant frequencies. In this paper we inserted the metalized holes in the structure as shown in figure 1 are arranged in such a way that it produces wideband bandpass filter with minimum attenuation by adjusting various parameters such as $\mathrm{p}$ (pitch length), $\mathrm{d}$ ( via diameter), $\mathrm{W}_{\mathrm{c}}$ (distance between two metallic arrays).

L

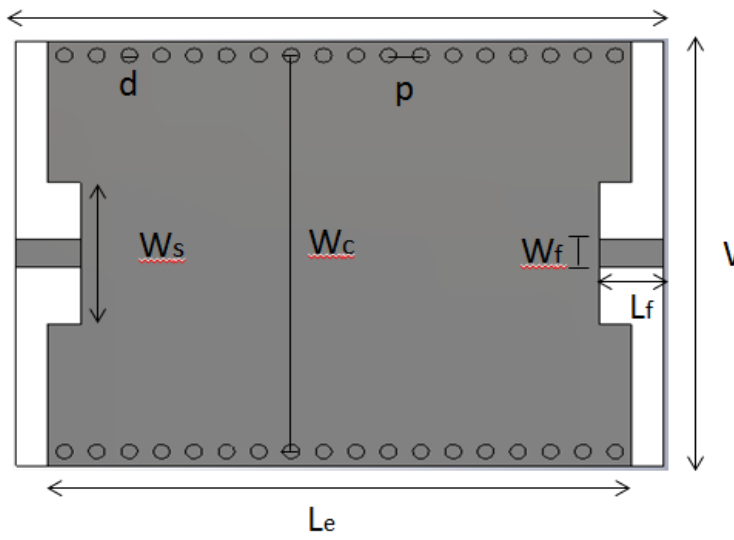

Figure 1: Substrate Integrated Waveguide Bandpass Filter Structure

The inserted metallic holes reduces the size of structure in comparison with [21]. Major role of improving the pass band performance of structure is to use a conductor backed coplanar waveguide, which is used to connect SIW by cutting the slots on input and output sides of structure. By increasing the length of slot electric coupling and magnetic coupling is improved which in turn improves the filter performance.

\section{SIW BANDPASS FILTER DESIGN PARAMETERS}

The SIW wide band pass filter with the metallic holes inserted inside the SIW with a geometrical systematic arrangement is shown in figure 1 . It gives more fractional bandwidth and compact size in comparison with [21] with improved return loss less than $56 \mathrm{~dB}$. The SIW band pass filter is designed at $80 \mathrm{GHz}$ center frequency. Finally we introduce the following empirical design formulae of the proposed SIW band pass filter whose fractional bandwidth is about $10.5 \%$.

$$
\begin{aligned}
& W=\frac{2.14 c}{f_{c} \sqrt{\epsilon_{r}}} \\
& \mathrm{~L}_{\mathrm{e}}=1.2 * \mathrm{~W} \pm \mathrm{d}
\end{aligned}
$$

Where $\mathrm{c}$ is the speed of light, $€_{\mathrm{r}}$ is relative permittivity of material and $f_{c}$ is center frequency. To minimize the radiation loss and return loss following conditions must be satisfied:

$$
\begin{aligned}
& \mathrm{d} / \mathrm{p} \geq 0.5 \\
& \mathrm{~d} / \mathrm{W}_{\mathrm{c}}<0.4
\end{aligned}
$$

Where $\mathrm{d}$ is diameter of vias, $\mathrm{p}$ is called pitch length or spacing between two vias, $\mathrm{W}_{\mathrm{c}}$ is distance between two metallic arrays. Metallic holes are inserted along the side walls of structure with parmeters $d, p$ and $\mathrm{W}_{\mathrm{c}}$ satisfying above equations which help in reducing the size of filter and wider passband is achieved as shown in Figure 2. Conductor backed coplanar waveguide is inserted in SIW as transition to obtain sharper skirt. The SIW structure is designed by using a substrate with relative permittivity, $€_{\mathrm{r}}$ of 2.2 and height of $0.762 \mathrm{~mm}$. The following table 1 gives the parametric values of filter design with matched port configuration at $50 \Omega$.

Table 1: Substrate Integrated Waveguide (SIW) Bandpass filter Parameters. Unit: mm

\begin{tabular}{|c|c|}
\hline Le & $7.2 \mathrm{~mm}$ \\
\hline $\mathbf{L}$ & $8 \mathrm{~mm}$ \\
\hline $\mathbf{W}_{\mathbf{c}}$ & $5.6 \mathrm{~mm}$ \\
\hline $\mathbf{W}$ & $6 \mathrm{~mm}$ \\
\hline $\mathbf{W}_{\mathbf{f}}$ & $0.4 \mathrm{~mm}$ \\
\hline $\mathbf{W}_{\mathbf{s}}$ & $2 \mathrm{~mm}$ \\
\hline $\mathbf{P}$ & $0.4 \mathrm{~mm}$ \\
\hline $\mathbf{D}$ & $0.2 \mathrm{~mm}$ \\
\hline Lf & $0.8 \mathrm{~mm}$ \\
\hline
\end{tabular}

Where $L_{e}$ is the length of SIW, $L$ is structure length, $W_{c}$ is distance between two metallic arrays, $\mathrm{W}$ is width of SIW, $\mathrm{W}_{\mathrm{f}}$ is feed line width also known as coplanar waveguide and $\mathrm{W}_{\mathrm{s}}$ is slot width, $\mathrm{p}$ is pitch length, $\mathrm{d}$ is diameter of vias and $\mathrm{L}_{\mathrm{f}}$ is length of feed line.

\section{SIMULATED RESULT}

We use CST microwave studio suite to carryout simulations and optimize the filter size. Full wave simulation response is shown in figure 2. $\mathrm{S}_{11}$ parametric curve shows the return loss and $S_{21}$ parametric curve shows insertion loss. The 3-Pole filtering characteristics represents the $3 \mathrm{~dB}$ bandwidth of 8.4 $\mathrm{GHz}$ with fractional bandwidth of $10.5 \%$ depicting minimum insertion loss $0.1 \mathrm{~dB}$ and return loss less than $56 \mathrm{~dB}$.

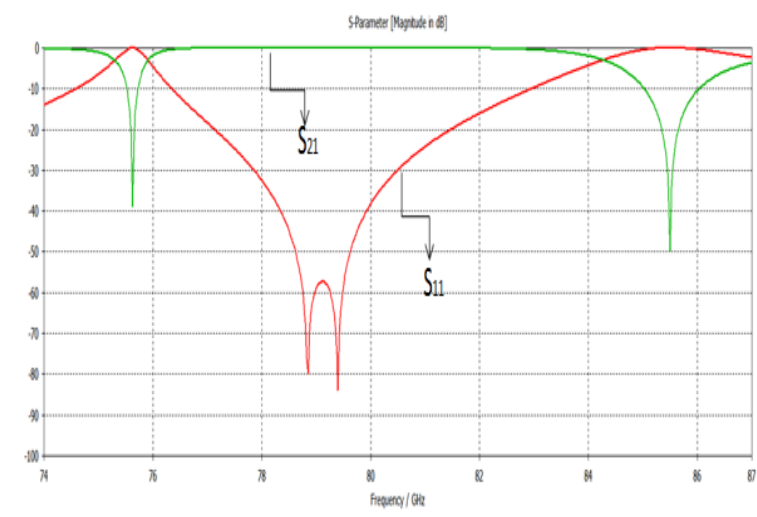

Figure 2: Simulated result of 3- Pole Substrate Integrated waveguide Bandpass filter depicting Insertion loss (S21) and return loss $(\mathrm{S} 11)$

\section{CONCLUSION}

This research paper presents a novel compact SIW band pass filter design criterion. The proposed filter design is simulated on CST microwave studio software. The simulated results show good pass band performance with $0.1 \mathrm{~dB}$ insertion loss 
and minimum $56 \mathrm{~dB}$ return loss at $80 \mathrm{GHz}$ center frequency. The fractional bandwidth obtained is $10.5 \%$. The filtering characteristics are improved using conductor backed coplanar waveguide. The proposed band pass filter is of compact size and wide bandwidth. The filter is suitable for various applications in $\mathrm{W}$ - band communication.

\section{ACKNOWLEDGEMENT}

This work was supported by Centre for Applied Research (CARE) Department at Indian Institue of Technology (IIT) Delhi.

\section{REFERENCES}

[1] D.Deslandes and K.Wu,"Integrated micro strip and rectangular waveguide in planar form," IEEE Micro. Wireless Comp. Lett., vol.11, no. 2, 68 -70, June2001.

[2] K.wu,'Integration and interconnects techniques of planar and nonplanar structures for microwave and millimeter wave circuits-current status and future trend," in proc. Asia-Pacific Microwave conf., Taipei, Taiwan, 411-416, Dec. 2001

[3] H. Uchimura, T. Takenoshita, and M. Fujii, "Development of a laminated waveguide," IEEE Trans. Micro. Theory Tech., vol. 46,no.12, 2438 -2443 1998.

[4] Y. Cassivi, L. Perregrini, K. Wu, and G. Conciauro, "Low-cost and high-millimeter-wave resonator using substrate integrated waveguide technique," Eur. Microwave Conf., Montreal, Canada, 2002.

[5] Y. Cassivi and K. Wu, "Low cost microwave oscillator using substrate integrated waveguide cavity," IEEE Microw. Wireless Comp. Lett., vol. 13, no. 2, 48 -50, 2003.

[6] S. Germain, D. Deslandes, and K. Wu, "Development of substrate integrated waveguide power dividers," Proc. IEEE Electrical Computer Engineering Conf.,vol. 3, $1921-1924,2003$.

[7] W. Q. Che, E. K. N. Yung, and K. Wu, "Millimeterwave ferrite phase shifter in substrate integrated waveguide (SIW)," IEEE AP-S Int. Microwave Symp. Dig., vol. 4, 887 -890, 2003

[8] L. Yan, W. Hong, G. Hua, J. X. Chen, K. Wu, and T. J. Cui, "Simulation and experiment on SIW slot array antennas," IEEE Microw. Wireless Compon. Lett., vol. 14, no. 9, $446-448,2004$

[9] Orazio, K. Wu, and J. Helszajn, "A substrate integrated waveguide degree-2 circulator," IEEE Micro. Wireless Comp. Lett., vol. 14, no. 3, .207-209 2004

[10] Hao, Z. C., Hong, W., Chen, X. P., Chen, J. X., Wu, K. "Planar diplexer for microwave integrated circuits," IEEE Proc. Microwaves, Antennas Propagation, vol. 152 , no. $6,455-459,2005$.
[11] Hao, Z. C., Hong, W., Chen, J. X.., Zhou, H. X., WU, $\mathrm{K}$,"Single-layer substrate integrated waveguide directional couplers," IEEE Proc. Microwaves, Antennas and Propagation, vol. 153, no. 5, 426-431, 2006.

[12] D. Deslandes and K. Wu,"Single-substrate Integration Technique of Planar Circuits and Waveguide Filters," IEEE Trans. Micro. Theory Techs., vol. 53, no. 9, 2968 2977 June 2003.

[13] Zhang-Cheng Hao, Ji-Xin Chen, Xiao-Ping Chen, and $\mathrm{Ke} \mathrm{Wu}$," Compact Super-Wide Bandpass Substrate Integrated Waveguide (SIW) Filters," IEEE Trans. Micro. Theory Techs., vol. 53, No. 9, September 2005.

[14] Ke. Wu. Yu Lin Zhang, Wei Hong, "Novel Substrate Integrated Waveguide Cavity Filter With Defected Ground Structure," IEEE Trans. Micro. Theory Tech., Vol. 53, No. 4, April 2005.

[15] X.C. Zhang,J. Xu.," Novel Band-pass substrate integrated waveguide (SIW) filter based on complementary split-ring resonators(CSRRs)," Progress in Electromagnetic Research, Vol. 72,. 39-46, 2007.

[16] Z. C. Hao, W. Hong, X. P. Chen, J. X. Chen, K. Wu, and T. J. Cui,"Multilayered substrate integrated waveguide (MSIW) elliptic filter," IEEE Microw. Wireless Compon. Lett., vol. 15, no. 2, . 95-97, Feb.2005.

[17] Amari,s. and U. Rosenberg, "Chraracteristics of Cross(bypass) coupling through higher/lower order modes and their alications in elliptic filter design," IEEE Trans. Microw. Theory Techs., Vol. 53, No. 10, 31353141,2005

[18] Hung-Yi Chine, Tze-Min shen, "Miniaturized Bandpass Filters With Double-Folded Substrate Integrated Waveguide Resonators in LTCC," IEEETrans. Micro. Theory Techs., vol. 57, no.7, 1774 -1782, July 2009.

[19] Yuanqing Wang, Wei Hong,Yuandan Dong, Bing Liu, Hong Jun Tang, Jixin Chen, Xiaoxin Yin, and Ke Wu, "Half Mode Substrate Integrated Waveguide (HMSIW) Bandpass Filter," IEEE Microw. Wireless Comp. Lett, Vol.17, No. 4, 265-270, April 2007.

[20] Peng Chu, Wei Hong,Linlin Dai,Hongjun Tan,Jixin Chen,ZhangchengHao,Xicheng Zhuand KeWu, "A Planar Bandpass Filter Implemented With a Hybrid Structure of Substrate Integrated Waveguide and Coplanar Waveguide," IEEE Trans. Microw. Theory Techs., Vol. 62, NO. 2, February 2014.

[21] Changjun Liu and Kama Haung, "A Compact Substrate Integrated Waveguide Band-pass Filter," Progress in Electromagnetic Research Symposium Proceedings, 1135-1138, July 5-8, 2010. 